\title{
Areal downscaling of global climate models: an approach that avoids data remodeling
}

\author{
J. Charlery ${ }^{1, *}$, L. Nurse ${ }^{2}$ \\ ${ }^{1}$ Department of Computer Science, Mathematics and Physics, and ${ }^{2}$ Centre for Resource Management and Environmental \\ Studies (CERMES), University of the West Indies, Cave Hill Campus, PO Box 4, Barbados BB11000, West Indies
}

\begin{abstract}
Since the conceptualization and evolution of the global climate models (GCMs), the necessity to resolve the data generated to areal representations below the very large grid boxes of those models has also been apparent. Different approaches, such as statistical downscaling and regional climate modeling, have been developed over the past few years to address this issue. We present an approach to downscaling GCM output data to finer areal resolutions without having to remodel the GCM data. Our algorithm uses a combination of interpolation equations and the historical relationships of observation points within the geographical area of study to resolve the downscaled predicted values. A comparative analysis of the algorithm's results with those of a regional climate model which used the same GCM data as boundary conditions indicates that the algorithm's results may be more faithful to both the local climatology and the GCM output. Furthermore, in experiments conducted in Barbados for the case study, a mean of $78 \%$ of the values generated by this method were within $30 \%$ of the observed data, and a mean of $60 \%$ of the generated values fell within $20 \%$ of the observed values.
\end{abstract}

KEY WORDS: Climate model · GCM · Downscaling $\cdot$ Barbados $\cdot$ Climate variables $\cdot$ High resolution Resale or republication not permitted without written consent of the publisher

\section{INTRODUCTION}

Within the past 2 decades, many global climate models have been developed to simulate the climate scenarios of the future decades. These models (e.g. HadCM, CSIRO, GFDL, GISS, CCGM) are generally capable of representing the broad features of the global atmospheric circulation reasonably well, and have provided the fundamental framework on which developers can generate scenarios and formulate decision making processes (Houghton 1997, Nakicenovic et al. 2000, IPCC 2001, Dai 2006). Despite the utility of these models, their performance in reproducing regional climatic details is rather poor. This is particularly true for variables such as precipitation and surface wind speed. With respect to the simulation of regional climates, GCMs suffer from several limitations, including a lack of sufficiently detailed surface data, inability of model parameterizations to model fine scales, and computational time required for high resolution runs (Kim et al. 1984, von Storch et al. 1993, Murphy 1999, Pan et al. 2001, IPCC 2001, 2007a, Ichikawa 2004, Cook \& Vizy 2006, Emori 2006). Hence, most GCMs are run at relatively coarse spatial resolutions, generally $>2.0^{\circ}$ for both latitude and longitude (>200 km for middle latitudes).

The direct result of the poor spatial resolution of GCMs is a serious mismatch of scale between the available climate change scenarios and the scale of interest to many climate data users. This is particularly true for the generation of climate scenarios for small islands or in other bounded areas smaller than the resolution of the models. Attempts to bridge this gap have typically taken the form of semi-empirical downscaling approaches, which make use of the fact that GCMs are good predictors of large-scale variables and atmospheric conditions sufficiently far removed from the surface of the earth (Matyasovszky et al. 1994, Sailor \& Xiangshang 1999). The approach involves relating these large scale parameters (e.g. upper level 
winds, geopotential heights, and sea level pressure) to historical observations of the surface parameter of interest (temperature, precipitation, wind speed, etc.). Thereafter, a transfer function can be developed using a wide range of modeling tools such as linear regression, classification and regression tree analysis, or neural networks. Once the transfer function is developed, it is assumed to remain invariant under climate change and is applied to the large scale parameters from a GCM climate change scenario. The result is a projection of the surface parameter of interest under the conditions of the change in climate.

Wilby \& Wigley (1997) have divided these downscaling approaches into 4 categories: regression methods, weather pattern-based approaches, stochastic weather generators and limited-area modeling. Due to their ease of implementation and low computation requirements, regression methods implemented within regional models or statistical downscaling models have become the most widely used. These methods have thus gained acceptance in many developing countries where resources are limited.

A somewhat more refined method, which has been applied to temperature and rainfall, is an approach described as the bias-correction and spatial downscaling method presented by Wood et al. (2004). This method implements a quantile-based mapping of the probability density functions for the monthly GCM precipitation and temperature onto those of gridded observed data, spatially aggregated to the GCM scale. This mapping is then applied to plausible simulations of the GCMs. According to Maurer (2007), this allows the mean and variability of a GCM to evolve in accordance with the GCM simulation, while matching all statistical moments between the GCM and observations for the base period. Wood et al. (2004) and Maurer (2007) also showed that the technique compared favorably to other downscaling techniques and is computationally efficient.

Notwithstanding this, these downscaling methods also fall short in their applicability in areas where long periods of historical climate data observations are not available. This is the case for most tropical islands and many other local areas which are not directly represented by the resolution of the GCM gridscales.

This work seeks to go a step further in the process of advancing the downscaling techniques by incorporating the historical data from all the available data points (i.e. stations) in the domain area. The method attempts to establish quantitative statistical relationships between all the stations within the area in order to produce the fine resolution interpolations for local areas, where no historical records exist. The term 'domain' shall be used to refer to the area of interest where the downscaling is required.

\section{METHODS}

The methodology proposed is based on the principal argument that for small domains, the main modulators to the climatic elements' distribution within the domain, such as topography, proximity of bodies of water, etc., will continue to play the pivotal role in the local relative distribution of those elements, irrespective of the changes in the global climate drivers. Hence some degree of stationarity is being assumed in the individual contributions. We also argue that the physical forcing by large-scale atmospheric circulation is reflected in the GCM climatology at individual grid-points. The semi-empirical downscaling approach developed and presented in this study is a variation on the previously mentioned techniques. This approach first establishes an empirical model between all the available historical data stations within the domain, and then draws a comparative distribution of the local climate variables from the large-scale GCM variables. As a result, an obvious difference between this method and other approaches such as that of Wigley et al. (1990), which utilizes transforms derived from empirical relationships between a set of local climate variables and the same suite of variables from the GCM simulations, is that the empirical relationship for this method is derived from the distribution of the local climate variable, as indicated by the data stations. Hence, whereas methods such as Wigley et al. (1990) implement regression analyses to perform sub-grid scale interpolations through the usage of a series of predictors and predictands between the GCM and the local domain, in this method the downscaling is performed for one element at a time from the GCM, whose downscaled distribution over the domain is determined directly from the statistical and spatial relationships derived from the historical data within the domain. Further, unlike the Wigley et al. (1990) model, in this method downscaling of the desired element is not determined by correlating the GCM values with other meteorological elements.

The grid box values of the large-scale GCM output, which correspond to the domain within which the downscaling is required, are then adjusted within the empirical model to generate predictions for the local climate variable being considered. While precipitation is the local climate variable studied in this work, the approach is general enough to be applied to other surface variables of interest, as long as 'adequate' historical records exist to establish acceptable point-to-point correlations between the data stations provided and the domain mean to which they contribute. As with other downscaling methods, this algorithm can only be applied to variables for which there is direct equivalence between the station measurements and the GCM. 


\section{ALGORITHM}

The refining algorithm is used to generate fine-resolution computations for the area, based on the climatic distribution of a given element within that area. The optimal climatic distribution definition is one which is determined from long-term observations (possibly spanning many decades). However, shorter periods may also be used with the understanding that the degree of reliability of distribution of the element from such limited data may result in point-to-point analyses, which may be less dependable.

We start with the premise that a small area completely bounded within a larger area will maintain an acceptably stable empirical relationship with the larger area which circumscribes it in the long term mean, if the entire area is uniformly exposed to some particular stimulus. Therefore, if we consider a physical space, where Area B is completely bounded by Area A, then an empirical relationship to compute the areal mean value of $B$ for some time instance, when the mean value of Area $\mathrm{A}$ is provided for that same instance, can be expressed simply as:

$$
\text { Areal mean of } B=\frac{\bar{X}_{B}\left(X_{A}\right)}{\bar{X}_{A}}
$$

where $\overline{\mathrm{X}}_{\mathrm{A}}=$ long term area mean for $\mathrm{A}, \overline{\mathrm{X}}_{\mathrm{B}}=$ long term area mean for $\mathrm{B}$, and $\mathrm{X}_{\mathrm{A}}=$ an instance areal mean for A.

The steps to the algorithm are therefore defined as follows:

(1) Start with available historical data from as many stations as possible within the domain and its vicinity, if available. The preference is for as many stations as possible within the area corresponding to the GCM grid boxes which superimpose the area of interest.

(2) Compute the mean of the meteorological element for each station within the domain for the temporal resolution (daily, monthly, etc.) for which the downscaling will be performed.

(3) Using all the stations, compute the areal mean for the domain.

(4) Determine the percentage contribution of each station to the areal mean. That value will be used as the station's coefficient to the areal mean.

(5) Get the baseline mean used by the GCM for the meteorological element within the GCM grid box which superimposes the area of interest.

(6) Use the domain's element mean and the GCM grid box baseline mean to create a relationship index between the grid box's baseline average and the domain's historical average for the element. (For any time slice, the element's mean areal value for the domain can be expressed as the product of the relationship index and the GCM grid box value.)
(7) For the time slice required, obtain the value of the element from the GCM grid box which corresponds to the required area of the domain. In the event of multiple grid boxes $(2,3$ or 4$)$ connecting over the domain, one of 2 options can be employed: either use the mean of the grid boxes or sub-divide the domain to correspond to the areas superimposed by the individual GCM grid boxes.

(8) The predicted element value for each station can then be computed as the product of the computed mean of the domain and the coefficient to the mean for the station.

(9) Use interpolation techniques to generate the predicted distribution over the required domain.

From the steps cited, it becomes clear that some historical knowledge of the areal distribution of the element being considered is required. This is achieved in Steps 1 to 4 . In Steps 5 and 6, the relationship between the GCM baseline climatology and the actual climatology of the domain is established. As with the other statistical downscaling models, the argument can be made that optimal comparison would be one where the baseline period for both the GCM and the domain are the same. However, for this work the hypothesis is premised not so much on matching of timelines, but is based on the proportional distribution of the meteorological element over the desired domain, during an instance when the mean is not biased by extremes.

Hence, once the areal distribution is properly captured by the available historical data, then the changes indicated by the GCMs can be redistributed accordingly within the domain. This technique, although having some foundation in the method used in other studies (such as Wilby \& Wigley 1997, Wilby et al. 2002 , 2003), adopts a process which is different from those previous methods. In Steps 8 and 9 the GCM values are modified, redistributed and interpolated to reflect the climatology of the local domain.

\section{CASE STUDY - RAINFALL PROJECTIONS FOR BARBADOS}

Barbados is located at $13^{\circ} \mathrm{N}, 59^{\circ} \mathrm{W}$, and has an area of $431 \mathrm{~km}^{2}$. Data were obtained from 14 stations scattered throughout the island, providing monthly data between 1960 and 2007 (Fig. 1). The mean monthly rainfall data observed at those stations during 19601999 are provided in Table 1.

\subsection{Barbados climate}

Barbados is the easternmost island of the Caribbean Archipelago. Its atmospheric conditions are almost exclusively controlled by the variations in the North Atlantic 


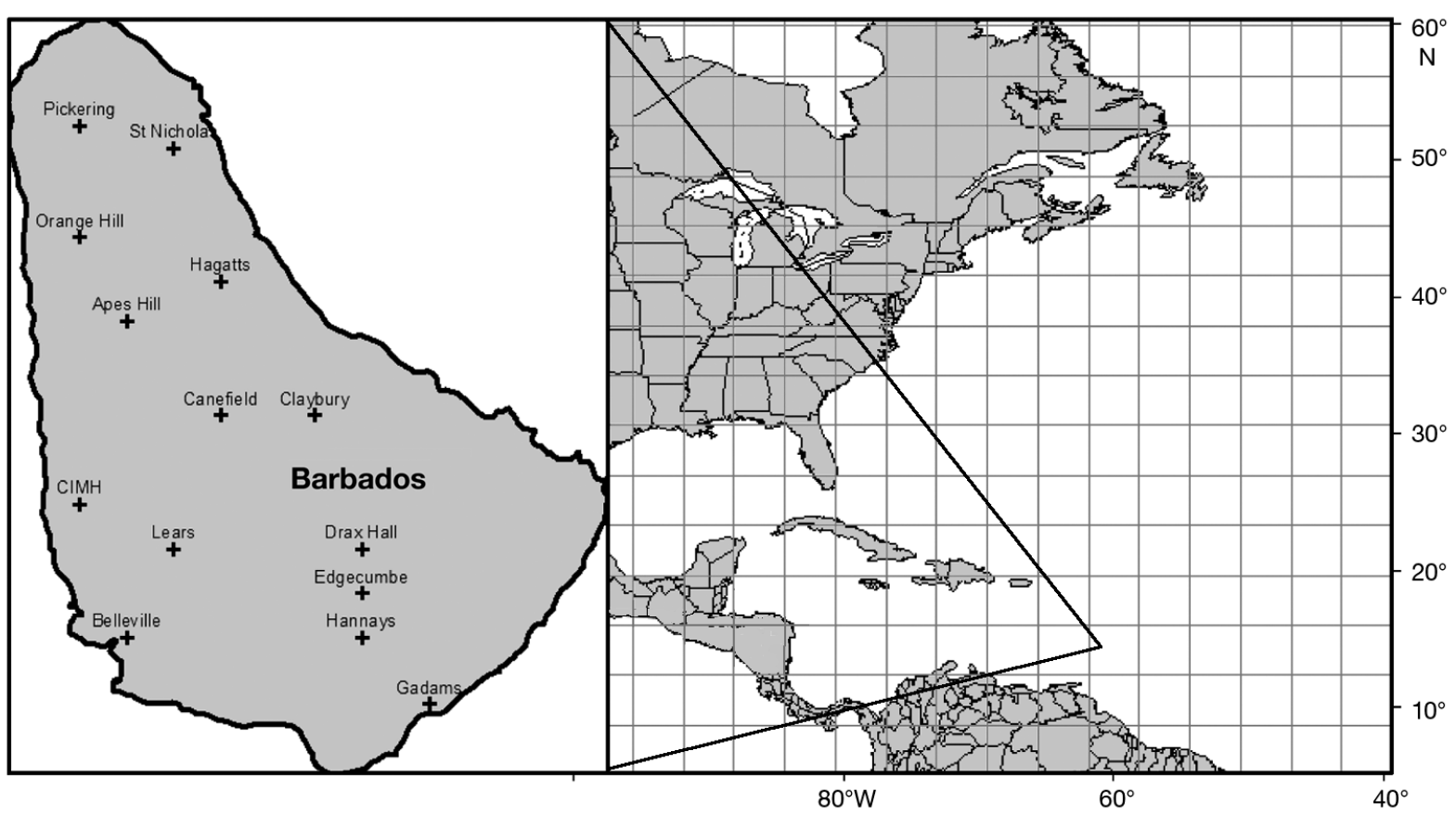

Fig. 1. HadCM3 grid boxes with location of Barbados and rainfall stations

high-pressure system. The climate is characterized by an annual wet and dry season during June to November and February to April, respectively. The wet season coincides with the Atlantic hurricane season and most of the rainfall is produced by tropical disturbances which pass through the Eastern Caribbean. The mean annual rainfall between 1960 and 1999 was $1428 \mathrm{~mm}$, or about $119 \mathrm{~mm}$ $\mathrm{mo}^{-1}$. On average there are $190 \mathrm{~d} \mathrm{yr}^{-1}$ with $>0.1 \mathrm{~mm}$ of rainfall. The driest month is March, when mean rainfall is $\sim 51 \mathrm{~mm}$. The wettest month is November with mean rainfall of $\sim 210 \mathrm{~mm}$. Rainfall is characterized by a high-rainfall zone extending from the higher-elevation central part of the island towards the west and northwest sections. The low-lying coastal regions of the extreme north and the south typically have the lowest rainfall (see the 'Observed climatology' column of Supplement 1, available at www. int-res.com/articles/suppl/c043p241_supp.pdf.

The climate is tropical maritime, with a mean annual relative humidity of $76 \%$ and a mean monthly relative humidity ranging from $71 \%$ in February-May to $81 \%$ in October-November. The annual mean temperature is $26.0^{\circ} \mathrm{C}$, with the highest (lowest) monthly mean maximum temperature of $30^{\circ} \mathrm{C}\left(21^{\circ} \mathrm{C}\right)$ between April and October (January and March).

\subsection{Models and data}

For this case study, the Hadley Centre's GCM HadCM3 has been selected to provide GCM data for the 2080s within the grid box where the island of Barbados is located. It should be noted that this GCM was used simply because of the availability of its outputs. No attempt is being made to promote or evaluate the appropriateness of any specific GCM model. For an RCM comparative analysis, the outputs from the Hadley Centre's RCM model PRECIS are also presented for a smaller subset area of the GCM grid box. It should be noted that the area of Barbados is approximately $1 \%$ of a typical GCM grid box, and roughly equivalent to the area of a single PRECIS grid box. Further, the GCM's grid box in which Barbados is located is characterized as an ocean grid box. We should also point out that no attempt is being made to promote or suggest that the PRECIS model is the best or most appropriate option for dynamic downscaling, but the easy availability of its outputs allows a quick and ready, if simple, comparison.

The PRECIS model's initialization and boundary data were supplied by the HadCM3 model and the grid boxes were defined at $0.22^{\circ}$ latitude, which translates to approximately $25 \times 25 \mathrm{~km}$. Kriging (Stein 1999) was chosen simply because of its ability to perform interpolations outside the polygon created by the data points - a feature not available with other interpolation methods such as inverse distance weighting to a power (Fisher et al. 1987), triangulation with linear interpolation (Lee \& Schachter 1980), natural neighbour (Laurent 1994), and minimum curvature (Smith \& Wessel 1990). Direct area downscaling, on which the present study is based, is presented for the very small domain bounded by the island. 
Based on the 14 rainfall stations which provided data for the domain, the coefficients of the mean areal rainfall for each station and for each month are computed and provided in Table 2. The available data set for Barbados was from 1960 to 2007. The coefficients were calculated for the period 1960-1999.

\subsection{Model performance}

To assess the model's performance with actual observations, which were not included in the derivation of the coefficients, 3 time periods were chosen: the wettest and driest years (2004 and 2003, respectively), and a year when rainfall was approximately midway between the 2 extremes (2000). The rainfall in 2003 was not substantially lower than the mean for 1960-1999. However, it was the driest year available in the 2000-2007 data set, and hence was used as the 'dry year' for comparison.
Coefficients from Table 2 were applied to the areal rainfall in Barbados for 2000, 2003 and 2004 and the results comparing observed and predicted values are presented in Supplement 1. Some observed values were not available for comparison (Canefield: all months in 2000; Claybury: Oct-Dec, 2004; Hannays: all months in 2004; Lears: all months in 2003 and St. Nicholas: May-Jun, 2004). With this sample, the best results were obtained during the wet year (2004), when 86 and $70 \%$ of model predictions (128 out of 149 and 105 out of 149, respectively) were within 30 and $20 \%$ of the observed values, respectively. In the dry year (2003), 71 and $55 \%$ of model predictions (111 out of 156 and 86 out of 156, respectively) were within 30 and $20 \%$, respectively of observed values. Similar results were also observed during the average year (2000), when 79 and $56 \%$ of model predictions (124 out of 156 and 87 out of 156 , respectively) were within 30 and $20 \%$ of observed values.

Table 1. Monthly mean observed rainfall (mm) in Barbados, 1960-1999

\begin{tabular}{|c|c|c|c|c|c|c|c|c|c|c|c|c|}
\hline Station & Jan & Feb & Mar & Apr & May & Jun & Jul & Aug & Sep & Oct & Nov & Dec \\
\hline Apes Hill & 102.4 & 77.4 & 74.8 & 92.1 & 103.7 & 145.0 & 193.1 & 221.6 & 237.7 & 260.6 & 247.7 & 166.2 \\
\hline Belleville & 47.4 & 36.2 & 32.6 & 41.3 & 43.9 & 81.6 & 111.8 & 154.5 & 142.4 & 172.0 & 133.1 & 78.6 \\
\hline $\mathrm{CIMH}$ & 52.7 & 39.0 & 42.8 & 50.1 & 48.9 & 84.8 & 124.8 & 176.6 & 152.4 & 205.2 & 171.6 & 89.3 \\
\hline Canefield & 89.9 & 71.1 & 71.4 & 82.4 & 90.4 & 138.0 & 181.1 & 209.8 & 217.8 & 246.7 & 222.8 & 152.3 \\
\hline Claybury & 91.6 & 63.6 & 60.5 & 78.5 & 93.2 & 128.5 & 171.1 & 193.6 & 197.6 & 247.6 & 205.3 & 156.0 \\
\hline Drax Hall & 73.8 & 54.3 & 52.4 & 71.3 & 81.0 & 101.4 & 142.6 & 174.4 & 169.9 & 203.3 & 181.2 & 121.6 \\
\hline Edgecumbe & 69.5 & 52.3 & 47.8 & 68.4 & 73.0 & 102.9 & 144.5 & 166.0 & 168.5 & 199.1 & 178.4 & 123.5 \\
\hline G. Adams & 59.4 & 41.5 & 39.1 & 53.4 & 63.8 & 88.1 & 128.2 & 139.7 & 143.8 & 166.1 & 149.1 & 93.6 \\
\hline Haggatts & 71.6 & 51.4 & 50.5 & 59.7 & 76.8 & 107.1 & 146.5 & 158.6 & 178.1 & 213.0 & 201.3 & 113.0 \\
\hline Hannays & 61.6 & 46.2 & 41.2 & 55.4 & 58.0 & 88.6 & 121.8 & 156.0 & 150.2 & 189.0 & 156.8 & 101.6 \\
\hline Lears & 77.8 & 55.6 & 52.0 & 69.1 & 73.7 & 106.7 & 154.8 & 185.0 & 185.1 & 220.0 & 184.6 & 127.8 \\
\hline Orange Hill & 81.7 & 59.5 & 59.8 & 75.2 & 78.9 & 111.6 & 159.3 & 187.2 & 191.8 & 223.1 & 215.4 & 132.3 \\
\hline Pickerings & 63.7 & 47.1 & 41.8 & 54.1 & 68.0 & 95.3 & 144.2 & 163.4 & 177.9 & 198.3 & 176.7 & 107.5 \\
\hline St. Nicholas & 63.7 & 47.6 & 46.8 & 65.6 & 59.2 & 91.7 & 131.9 & 159.9 & 175.4 & 196.9 & 189.2 & 103.4 \\
\hline Mean & 71.9 & 53.1 & 51.0 & 65.5 & 72.3 & 105.1 & 146.8 & 174.7 & 177.8 & 210.1 & 186.7 & 119.1 \\
\hline
\end{tabular}

Table 2. Coefficients of monthly mean rainfall, 1960-1999

\begin{tabular}{|c|c|c|c|c|c|c|c|c|c|c|c|c|}
\hline Station & Jan & Feb & Mar & Apr & May & Jun & Jul & Aug & Sep & Oct & Nov & Dec \\
\hline Apes Hill & 1.43 & 1.46 & 1.44 & 1.41 & 1.42 & 1.39 & 1.33 & 1.27 & 1.32 & 1.27 & 1.33 & 1.40 \\
\hline Belleville & 0.66 & 0.68 & 0.64 & 0.62 & 0.60 & 0.76 & 0.75 & 0.88 & 0.80 & 0.81 & 0.70 & 0.67 \\
\hline CIMH & 0.74 & 0.74 & 0.85 & 0.74 & 0.65 & 0.80 & 0.84 & 1.02 & 0.85 & 0.97 & 0.90 & 0.76 \\
\hline Canefield & 1.25 & 1.34 & 1.41 & 1.26 & 1.22 & 1.33 & 1.26 & 1.20 & 1.21 & 1.22 & 1.21 & 1.27 \\
\hline Claybury & 1.27 & 1.21 & 1.18 & 1.20 & 1.29 & 1.24 & 1.18 & 1.10 & 1.11 & 1.20 & 1.13 & 1.30 \\
\hline Drax Hall & 1.02 & 1.02 & 1.03 & 1.08 & 1.10 & 0.98 & 0.99 & 0.99 & 0.96 & 0.99 & 0.97 & 1.02 \\
\hline Edgecumbe & 0.97 & 0.98 & 0.95 & 1.06 & 0.99 & 0.97 & 0.97 & 0.95 & 0.96 & 0.93 & 0.95 & 1.04 \\
\hline G. Adams & 0.83 & 0.78 & 0.77 & 0.81 & 0.90 & 0.83 & 0.87 & 0.80 & 0.81 & 0.78 & 0.79 & 0.78 \\
\hline Haggatts & 0.99 & 0.95 & 0.99 & 0.92 & 1.07 & 1.02 & 0.99 & 0.91 & 1.02 & 1.00 & 1.08 & 0.95 \\
\hline Hannays & 0.86 & 0.85 & 0.83 & 0.89 & 0.87 & 0.85 & 0.83 & 0.90 & 0.85 & 0.87 & 0.86 & 0.87 \\
\hline Lear & 1.08 & 1.05 & 1.02 & 1.05 & 1.02 & 1.01 & 1.04 & 1.06 & 1.04 & 1.03 & 0.99 & 1.06 \\
\hline Orange Hill & 1.14 & 1.13 & 1.17 & 1.16 & 1.09 & 1.04 & 1.07 & 1.07 & 1.09 & 1.05 & 1.14 & 1.11 \\
\hline Pickerings & 0.89 & 0.89 & 0.81 & 0.82 & 0.95 & 0.89 & 0.98 & 0.94 & 1.00 & 0.93 & 0.92 & 0.90 \\
\hline St. Nicholas & 0.88 & 0.91 & 0.92 & 0.98 & 0.85 & 0.90 & 0.91 & 0.91 & 0.97 & 0.95 & 1.02 & 0.86 \\
\hline
\end{tabular}




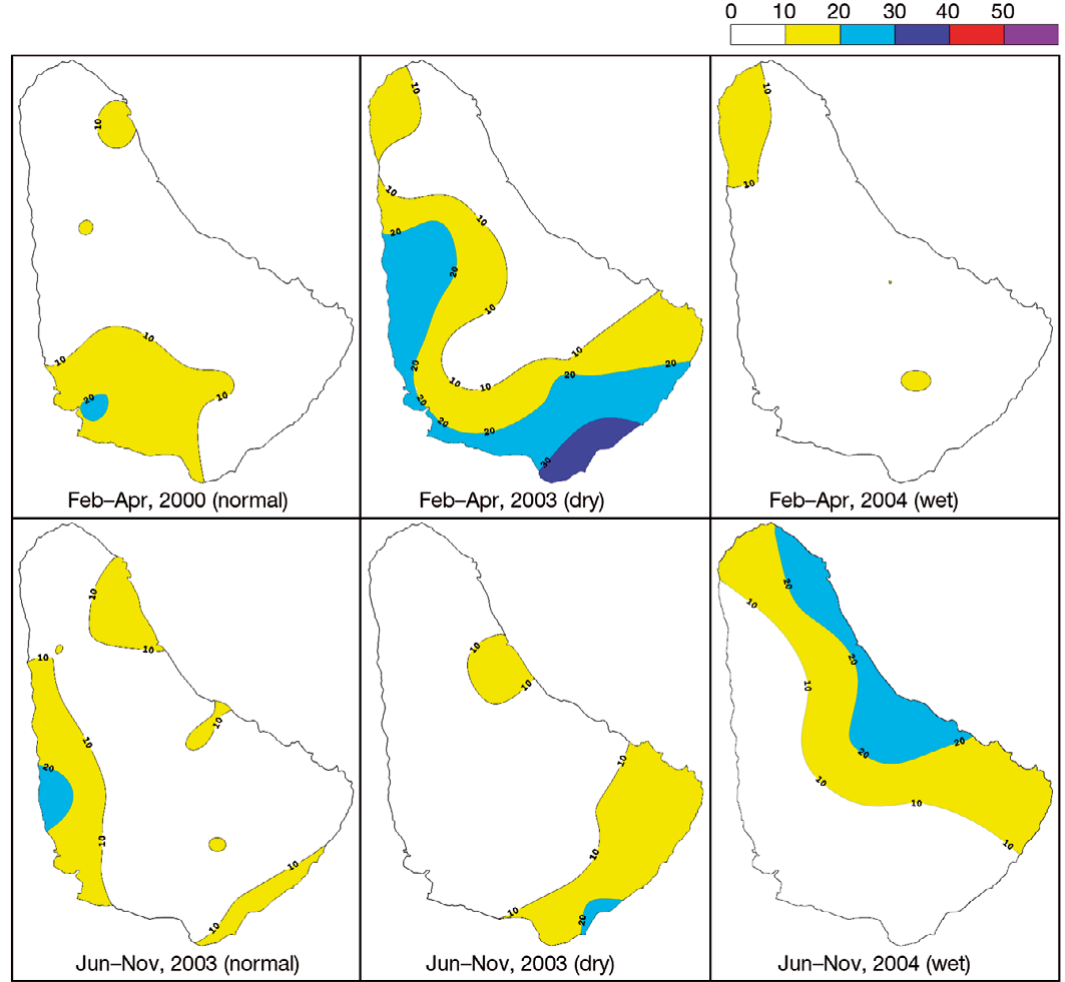

Fig. 2. Sum of absolute rainfall values ( $\mathrm{mm}$ ) of all Direct Area Downscaling errors over the domain, during the dry season (February to April) and the wet season (June to November) for the years 2000, 2003 and 2004 behaviour'. The first incident (February to April 2003) is the dry season of a dry year while the second incident (June to November 2004) is the wet season of a wet year. Since the climate coefficients of the domain that are used by DAD are based on a mean distribution, which itself is not characterized by extreme events, it would not be unreasonable to expect the larger errors to coincide with those extreme events. Despite this, for more than $3 / 4$ of the domain, the error was $<20 \%$. Paradoxically, the wet season in the dry year (June to November 2003) and the dry season in the wet year (February to April 2004) produced relatively small errors throughout the domain. The second observation is that in the near normal year (2000), the errors were quite similar in both the dry and the wet seasons. During this year, apart from a small pocket in the southwestern part of the domain where the error ranged between 20 and $30 \%$, the error for the remainder of the domain was generally $<10 \%$.
There was no apparent bias in the distribution or quantity of the predicted rainfall with respect to locations within the domain during these 3 years. However, the largest deviations occurred in May 2003 (dry year). This is possibly because May is the transition period between the dry and wet seasons, and hence the timing of wet season onset is not very well captured. This error is substantially reduced when April, May and June are grouped together as one period.

\subsection{Model performance analysis}

The cumulative errors resulting from the difference between DAD's prediction and the observed rainfall values for the near average year (2000), the dry year (2003) and the wet year (2004) are presented in Fig. 2. In this cumulative error, the absolute values of the magnitude of the differences were simply summed together, both when DAD under-predicted or overpredicted the rainfall quantities, with the result representing the model error during those years.

Using this coarse method, the 2 periods with the largest expected errors are February to April 2003 and (to a lesser extent) June to November 2004. These 2 occurrences represent the 2 extremes of the 'climate

\subsection{Comparative results}

A plot of the 3 baselines is presented in Fig. 3. The rainfall quantities defined by the domain and PRECIS baselines are consistently greater than that of the GCM baseline. That difference is substantially wider during the latter half of the year.

Table 3 gives the HadCM3 GCM model's rainfall values for the grid box containing Barbados, including the baseline values (1960-1999) and the projections for

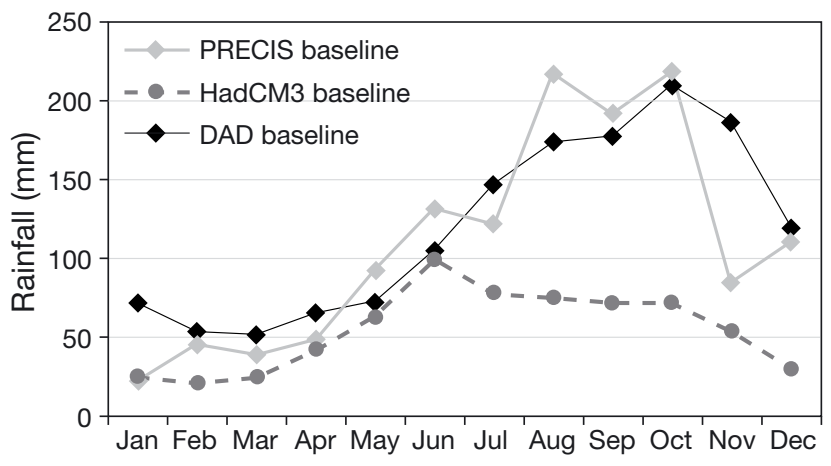

Fig. 3. Monthly baseline averaged rainfall (mm) for Barbados (1960-2000) as used by HadCM3 and PRECIS plotted against observed monthly average rainfall for the domain as used by Direct Area Downscaling (DAD) 
Table 3. HadCM3 GCM rainfall data (mm) for grid box over Barbados

\begin{tabular}{|lccccc|}
\hline Month & $\begin{array}{c}\text { Base- } \\
\text { line }\end{array}$ & $\begin{array}{c}\text { A2 } \\
\text { 2080s }\end{array}$ & $\begin{array}{c}\text { B2 } \\
\text { 2080s }\end{array}$ & $\begin{array}{c}\text { A2 } \\
\text { (\% change) }\end{array}$ & $\begin{array}{c}\text { B2 } \\
\text { (\% change) }\end{array}$ \\
\hline Jan & 24 & 22.3 & 23.8 & -7 & -1 \\
Feb & 21 & 17.4 & 17.6 & -17 & -16 \\
Mar & 24 & 19.7 & 25.9 & -18 & 8 \\
Apr & 42 & 29.8 & 29.8 & -29 & -29 \\
May & 63 & 30.2 & 39.1 & -52 & -38 \\
Jun & 99 & 29.7 & 41.6 & -70 & -58 \\
Jul & 78 & 28.1 & 49.9 & -64 & -36 \\
Aug & 75 & 22.5 & 40.5 & -70 & -46 \\
Sep & 72 & 25.9 & 48.2 & -64 & -33 \\
Oct & 72 & 40.3 & 58.3 & -44 & -19 \\
Nov & 54 & 24.3 & 56.7 & -55 & 5 \\
Dec & 30 & 22.5 & 28.8 & -25 & -4 \\
\hline
\end{tabular}

the SRES A2 and B2 scenarios. The projections suggest that by the 2080s, mean monthly rainfall in Barbados will decrease, but the magnitude of the decline will be much higher under the SRES A2 scenario than under B2. The only exceptions are the months of March and November under the B2 scenario, for which HadCM3 projects an increase in rainfall of 8 and $5 \%$, respectively, relative to the baseline. Also, the maximum monthly rainfall losses are projected to occur during the 'normal' rainy season (i.e. June to November).

The baseline used by the HadCM3 model is 19601999. For this case study, the same time period is used to define the domain baseline. Although we argue that the matching of timelines is not necessary for the domain baseline (since what is required is the accurate mapping of the meteorological element's proportional distribution across the domain), given that the full dataset was available, it was therefore used. The baseline for PRECIS on the other hand, is composed from a quasi-observed set of boundary data derived from an ECMWF reanalysis dataset (ECMWF: European Centre for Medium-Range Weather Forecasting), available for 1979-1993 inclusive. This baseline is normally referred to as ERA15.

A comparison of the DAD model and PRECIS for the A2 and B2 scenarios in the 2080s with respect to the behavior of the GCM is presented in Fig. 4. In both the A2 and B2 scenarios, the GCM simulation for the grid box containing Barbados is characterized by a significant reduction of rainfall below that of the baseline. The magnitude of that reduction is greatest between May and November, which coincides with the annual wet season. A plot of the domain climatological mean $(1960-1999)$ is also provided in these figures. The trend exhibited by the GCM is derived from the difference between the GCM baseline and its predicted value for the grid cell, and expressed as a percentage. The other plots (DAD, PRECIS and the historical mean) represent predicted rainfall values for the 2080 s, expressed in $\mathrm{mm}$.

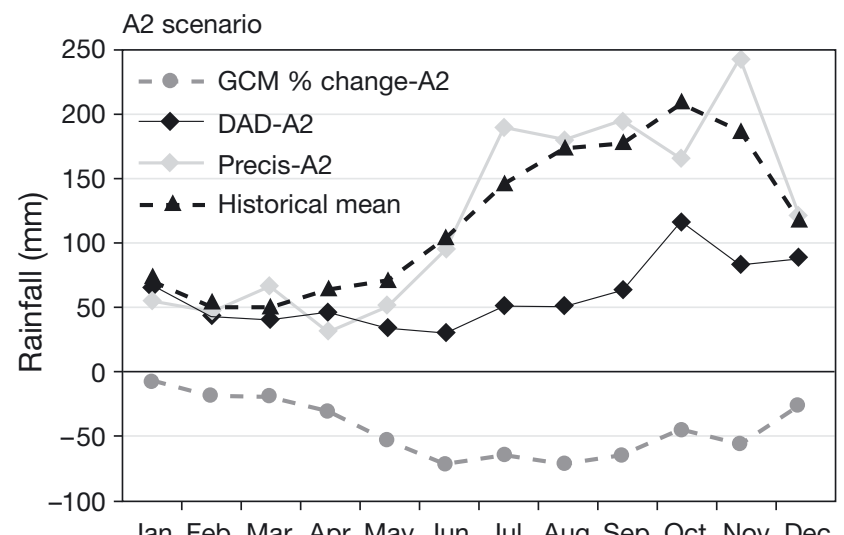

Jan Feb Mar Apr May Jun Jul Aug Sep Oct Nov Dec

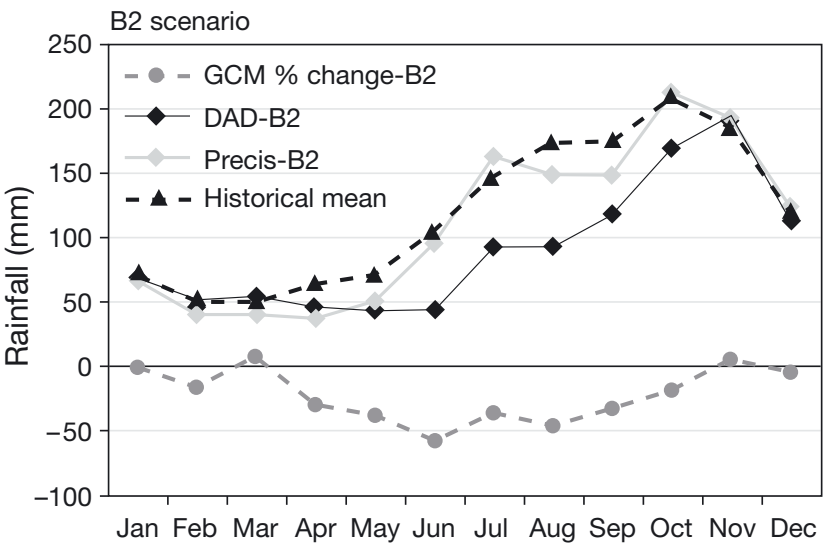

Fig. 4. Comparative 2080s rainfall projections ( $\mathrm{mm}$ ) for Barbados (based on HadCM3 percentage changes from the base line) for PRECIS and Direct Area Downscaling (DAD)

When projections from PRECIS and DAD are compared for the same time slice (i.e. 2080s), the sign of the precipitation change is similar. However, for both the A2 and B2 scenarios, the values produced by PRECIS and DAD are similar only for the drier season (January to May), but depart from each other during the wetter season (June to November) where PRECIS consistently projects significantly higher rainfall values than DAD (Fig. 4).

DAD faithfully and consistently represents the trend in the GCM output. This is also illustrated in Fig. 4. Percentage changes in the GCM trend are matched by proportional changes in magnitude in DAD simulations. In the case of PRECIS, similar consistency with respect to the GCM output is not as immediately apparent.

The full downscaled results of DAD and PRECIS for the 2080s, along with the domain's climatological mean and the HadCM3 grid box values are presented in Supplement 2, available at www.int-res.com/articles/suppl/ c043p241_supp.pdf, for each month, for both the SRES A2 and B2 scenarios. It should be noted that the primary objectives of this work were to ensure that the areal distribution of the meteorological element over the domain was maintained in the downscaling process, while at the same time allowing the changes to be dictated 
by the GCM. As Fig. 4 and Supplement 2, available at www.int-res.com/articles/suppl/c043p241_supp.pdf, illustrate, these objectives have been consistently adhered to in both the A2 and B2 results from DAD. In Figs. 4 \& 6 (and also reflected in the HadCM3 column in Figs. 5 \& 6) the overall differences between the climatological mean and the projections by DAD for both scenarios, as specified by the GCM, are immediately visible.

Outputs from DAD are always consistent, both spatially and temporally, with the climatological distributions over the domain. The orographic lifting which produces a climatological maximum rainfall area over the central and northwestern parts of the island reproduces both the maximum rainfall amounts in those areas and the orientation of the zone of maximum rainfall under both the A2 and B2 scenarios. The consistency between the observed climatology and outputs from DAD is also reflected in the seasonal distributions of rainfall (i.e. a distinct wet and dry season). On the other hand, those distinctions are not apparent in the PRECIS outputs.

\subsection{Climate change scenario}

The climate change scenario specified by the HadCM3 GCM for the 2080s, for both the A2 and B2 emission scenarios, is typified by a general reduction in rainfall below that provided by its baseline. In some cases, this reduction exceeds $50 \%$. In DAD, this drier climate of the 2080s retains the proportional spatial distribution characteristics defined by the mean observed climate, but results in significant differences during the traditional wet and dry seasons. Mean reductions between $21 \%$ (A2 scenario) and $12 \%$ (B2 scenario) during the expected dry season (February to April) indicated by the GCM apply to relatively small amounts of rainfall during that time. These changes, although significant numerically, represent a reduction in rainfall of only a few millimeters.

The wet season (June to November), on the other hand, is characterized by a much larger mean reduction of $61 \%$ (A2 scenario) and $31 \%$ (B2 Scenario), as indicated by the GCM. This large percentage reduction applies to relatively large amounts of rainfall, and the resulting changes are significant. However, as illustrated in Supplement 2, the timing of the rainfall seasonality remains unchanged with the dry season in February to April and the wet season in June to November.

\section{CONCLUSIONS}

There are 2 critical limitations in performing a climate change analysis for small areas. (1) Scale. As numerous authors (e.g. Wilby \& Wigley 1997, IPCC
2001, Wilby et al. 2002) have shown, GCMs provide the best projections, but do not adequately represent the local climate. This limitation has been addressed with some success by the implementation of statistical downscaling models which relate the GCM output to the climate of a data point. Despite its success, this approach leads us Limitation (2): as a requirement for statistical downscaling, daily observed data for 19601999 must be available to establish the statistical relationships between the GCM data and the observations. Even with this, the downscaled projection is only relevant for the particular point for which data are being used. The only other recourse is to perform some other dynamic downscaling which could reduce the GCM grid resolution to a scale that is more relevant to the area of interest.

These limitations are particularly restrictive, as for many domains where plausible future climate change analyses are required, observed data have either been inconsistent in their collection or simply unavailable. This is especially true for many small islands where the theoretical impact of future changes in climate could be dramatic. These limitations, combined with the limited downscaling capacities which frequently exist in the domains where it is desperately needed, were the principal drivers to the present study.

In this study we present a simple method which seeks to bridge the gap between GCMs and the relatively small local domain, whose climate may be misrepresented by GCM data. The method is also applicable where historical data are inconsistent or unavailable for the particular locality (as required by the statistical downscaling models), and at the same time it provides a fine resolution analysis for the entire area. Contrary to other dynamic downscaling models (such as PRECIS), which require many months to perform the computations at resolutions ranging from 100 to $2500 \mathrm{~km}^{2}$ grids on high-end workstations, this method requires only seconds on a basic personal computer to complete the downscaling computations for any given element, over the entire domain, at a very fine resolution. Moreover, in this method the behaviour of the downscaled element within the domain always responds faithfully to the guidance provided by the GCM. At the same time, the application ensures a faithful distribution of the element over the domain, as dictated by the physical influences affecting the distribution of climatalogical factors. However, the reliability of the model's fine resolution output is critically dependent on the availability of certain historical observations, either within or surrounding the desired domain. These observations must also reflect the local physical characteristics of the meteorological element in that general area. As a result, the better the available historical data is at representing the distribution over the domain, the better the downscaled outcome will be. 
Further, unlike other dynamic downscaling models which are directly linked to specific GCMs to provide the boundary data, this model is not restricted by data formats which are peculiar to a specific GCM, and is therefore completely independent. All that is required is the element value for the chosen grid box of a given GCM for the desired time instance. Consequently, once the relationships which govern the element's local distribution have been established, comparative computations - with data from a number of GCM simulations simultaneously - can be performed in a few minutes.

Small island states are among the countries that are most vulnerable to adverse effects of global climate change (Lal et al. 2002, Ebi et al. 2006, IPCC 2007a, Mimura et al. 2007). Yet there is still a dearth of studies on the vulnerability of small islands and, more specifically, climate scenarios and model outputs at spatial scales appropriate for islands. Indeed, the IPCC has lamented the fact that published literature in refereed journals relating to small islands and climate change during the period that elapsed between publication of its Third and Fourth Assessment Reports (i.e. in 20012007) was 'rather less' than what was produced in the period between publication of its Second and Third Assessment Reports (IPCC 2007b). It is therefore hoped that the present study, along with further refinements of the methodology (based on wider application and testing), will make a positive contribution to the modest but slowly growing body of literature that focuses on climate change projections at the scale of islands, especially where limited downscaling capacity exists.

\section{LITERATURE CITED}

Cook KH, Vizy EK (2006) Coupled model simulations of the West African monsoon system: 20th century simulations and 21st century predictions. J Clim 19:3681-3703

Dai A (2006) Precipiation characteristics in eighteen coupled climate models, Q J Am Meteorol Soc 19:4605-4630

Ebi KL, Lewis ND, Corvalan C (2006) Climate variability and change and their potential health effects in small island states: information for adaptation planning in the health sector. Environ Health Perspect 114:1957-1963

Emori S (2006) The reliability of future climate change projection by high-resolution climate models. Glob Environ Res 10:143-149

Fisher NI, Lewis T, Embleton BJJ (1987) Statistical analysis of spherical data. Cambridge University Press, Cambridge

Houghton J (1997) Global warming: the complete briefing. Cambridge University Press, Cambridge

Ichikawa A (2004) Global warming - the research challenges. A report of Japan's global warming initiative. Springer, Dordrecht

IPCC (2001) Climate change 2001: the scientific basis. Contribution of Working Group I to the Third Assessment Report of the IPCC. Cambridge University Press, Cambridge

IPCC (2007a) Climate change 2007: the physical science basis. Contribution of Working Group I to the Fourth Assessment Report of the IPCC. Cambridge University Press, Cambridge

IPCC (2007b) Climate change 2007: impacts, adaptation and vulnerability. Contribution of Working Group II to the Fourth Assessment Report of the IPCC. Cambridge University Press, Cambridge

Kim JW, Chang JT, Baker NL, Wilks DS, Gates WL (1984) The statistical problem of climate inversion: determination of the relationship between local and large-scale climate. Mon Weather Rev 112:2069-2077

Lal M, Harasawa H, Takahashi K (2002) Future climate change and its impacts over small island states. Clim Res 19:179-192

Laurent PJ (1994) Wavelets, images, and surface fitting. In: Le Mehaute A (ed). AK Peters, Natick, MA

Lee DT, Schachter BJ (1980) Two algorithms for constructing a Delaunay triangulation. Int J Comput Inf Sci 9:219-242

Matyasovszky I, Bogardi I, Duckstein L (1994) Comparison of two general circulation models to downscale temperature and precipitation under climate change. Water Resour Res 30:3437-3448

Maurer, EP (2007) Uncertainty in hydrologic impacts of climate change in the Sierra Nevada, California under two emissions scenarios. Clim Change 82:309-325

Mimura N, Nurse L, McLean RF, Agard J and others (2007) Small islands. In IPCC (ed) Climate change 2007: impacts, adaptation and vulnerability. Contribution of Working Group II to the Fourth Assessment Report of the IPCC. Cambridge University Press, Cambridge, p 678-716

Murphy J (1999) An evaluation of statistical and dynamical techniques for downscaling local climate. J Clim 12: $2256-2284$

Nakicenovic N, Alcamo J, Davis G, de Vries HJM and others (2000) IPCC Special Report on Emissions Scenarios. Cambridge University Press, Cambridge

Pan Z, Christensen JH, Arritt RA, Gutowski WJ Jr, Takle ES and Otenio F (2001) Evaluation of uncertainties in regional climate change simulations. J Geophys Res 106:1773517752.

Sailor D, Xiangshang L (1999) A semiempirical downscaling approach for predicting regional temperature impacts associated with climate change. J Clim 12:103-114

Smith WHF, Wessel P (1990) Gridding with continuous curvature splines in tension. Geophysics 55:293-305

Stein ML (1999) Interpolation of spatial data: some theory for kriging. Springer, New York, NY

von Storch H, Zorita E, Cubasch U (1993) Downscaling of global climate change estimates to regional scales: an application to Iberian rainfall in wintertime. J Clim 6: $1161-1171$

> Wigley TM, Jones P, Briffa K, Smith G (1990) Obtaining subgrid scale information from coarse resolution general circulation output. J Geophys Res 95:1943-1953

Wilby RL, Wigley TML (1997) Downscaling general circulation model output: a review of methods and limitations. Prog Phys Geogr 21:530-548

Wilby RL, Dawson CW, Barrow EM (2002) SDSM - a decision support tool for the assessment of regional climate change impacts. Environ Model Softw 17:145-159

Wilby RL, Tomlinson OJ, Dawson CW (2003) Multi-site simulation of precipitation by conditional resampling. Clim Res 23:183-194

Wood AW, Leung LR, Sridhar V, Lettenmaier DP (2004) Hydrologic implications of dynamical and statistical approaches to downscaling climate model outputs. Clim Change 62: $189-216$ 